\title{
$(\alpha-\psi)$-Contractive Mappings on Generalized Quasimetric Spaces
}

\author{
Erdal Karapınar ${ }^{1,2}$ and Hosein Lakzian ${ }^{3}$ \\ ${ }^{1}$ Department of Mathematics, Atilim University, Incek, 06836 Ankara, Turkey \\ ${ }^{2}$ Nonlinear Analysis and Applied Mathematics Research Group (NAAM), King Abdulaziz University, Jeddah, Saudi Arabia \\ ${ }^{3}$ Department of Mathematics, Payame Noor University, Tehran 19395-4697, Iran
}

Correspondence should be addressed to Hosein Lakzian; h_lakzian@pnu.ac.ir

Received 26 June 2014; Revised 30 July 2014; Accepted 30 July 2014; Published 18 August 2014

Academic Editor: Nawab Hussain

Copyright (C) 2014 E. Karapınar and H. Lakzian. This is an open access article distributed under the Creative Commons Attribution License, which permits unrestricted use, distribution, and reproduction in any medium, provided the original work is properly cited.

We consider the existence of a fixed point of $(\alpha-\psi)$-contractive mappings in the context of generalized quasimetric spaces without Hausdorff assumption. The obtained results extend several results on the topic in the literature.

\section{Introduction and Preliminaries}

In the last decade, quasimetric spaces have been one of the interesting topics for the researchers in the field of fixed point theory due to two reasons. The first reason is that the assumptions of quasimetric are weaker than the more general metric. Consequently, the obtained fixed point results in this space are more general and hence the corresponding results in metric space are covered. The second reason is the fact that fixed point problems in $G$-metric space (introduced by Mustafa and Sims [1]) can be reduced to related fixed point problems in the context of quasimetric space (see, e.g., $[2,3])$. Very recently, Lin et al. [4] introduced the notion of generalized quasimetric spaces and investigated the existence of a certain operator on such spaces. In this paper [4], the authors assumed that the generalized quasimetric space is Hausdorff to get a fixed point.

In this paper, we examine the existence of $(\alpha-\psi)$-contractive mappings in the context of generalized quasimetric space without the Hausdorffness assumption. Consequently, our results extend, improve, and generalize several results in the literature.

In what follows we recall the basic definitions and results on the topics for the sake of completeness. Throughout the paper, the symbols $\mathbb{R}, \mathbb{N}$, and $\mathbb{N}_{0}$ denote the real numbers, the natural numbers, and the positive integers, respectively.
Let $X$ be a nonempty set and let $d: X \times X \rightarrow[0, \infty)$. Then $d$ is called a distance function if, for every $x, y, z \in X$, it satisfies

$$
\begin{aligned}
& \left(d_{1}\right) d(x, x)=0 ; \\
& \left(d_{2}\right) d(x, y)=d(y, x)=0 \Rightarrow x=y ; \\
& \left(d_{3}\right) d(x, y)=d(y, x) ; \\
& \left(d_{4}\right) d(x, z) \leq d(x, y)+d(y, z) .
\end{aligned}
$$

Notice that if $d$ satisfies the conditions $\left(d_{2}\right),\left(d_{3}\right)$, and $\left(d_{4}\right)$, then $d$ is called a dislocated metric on $X$. If $d$ satisfies the conditions $\left(d_{1}\right),\left(d_{2}\right)$, and $\left(d_{4}\right)$, then $d$ is called a quasimetric on $X$. On the other hand, if $d$ satisfies the conditions $\left(d_{1}\right)-\left(d_{4}\right)$, then $d$ is called a metric on $X$.

One of the very natural generalizations of the notion of a metric was introduced by Branciari [5] in 2000 by replacing the triangle inequality assumption of a metric with a weaker condition, quadrilateral inequality.

Definition 1 (see [5]). Let $X$ be a nonempty set and let $d$ : $X \times X \rightarrow[0, \infty)$ be a mapping such that, for all $x, y \in X$ and for all distinct points $u, v \in X$ each of them different from $x$ and $y$, one has

(i) $d(x, y)=0$ if and only if $x=y$;

(ii) $d(x, y)=d(y, x)$; 
(iii) $d(x, y) \leq d(x, u)+d(u, v)+d(v, y)$ (quadrilateral inequality).

Then $(X, d)$ is called a generalized metric space (or shortly g.m.s).

We present an example to show that not every generalized metric on a set $X$ is a metric on $X$.

Example 2 (see, e.g., [4]). Let $X=\{t, 2 t, 3 t, 4 t, 5 t\}$ with $t>0$ be a constant, and we define $d: X \times X \rightarrow[0, \infty)$ by

(1) $d(x, x)=0$, for all $x \in X$;

(2) $d(x, y)=d(y, x)$, for all $x, y \in X$;

(3) $d(t, 2 t)=3 s$;

(4) $d(t, 3 t)=d(2 t, 3 t)=s$;

(5) $d(t, 4 t)=d(2 t, 4 t)=d(3 t, 4 t)=2 s$;

(6) $d(t, 5 t)=d(2 t, 5 t)=d(3 t, 5 t)=d(4 t, 5 t)=(3 / 2) s$,

where $s>0$ is a constant. Then $(X, d)$ is a generalized metric space, but it is not a metric space, because

$$
d(t, 2 t)=3 s>d(t, 3 t)+d(3 t, 2 t)=2 s .
$$

Despite the analogy between the definitions of metric and generalized metric their topological properties differ from each other. For example, for a generalized metric space $(X, d)$, we have the following.

$(P 1)$, a generalized metric, need not be continuous;

$(P 2)$, a convergent sequence in generalized metric space, need not be Cauchy;

(P3), an open ball $\left(B_{r}(x)=\{y \in X: d(x, y)<r\}, r>0\right)$, need not be open set;

$(P 4)$, a generalized metric space, need not be Hausdorff, and hence the uniqueness of limits cannot be guaranteed.

Example 3 (see [6], Example 1.1). Let $X=A \cup B$, where $A=$ $\{0,2\}$ and $A=\{1 / n: n \in \mathbb{N}\}$. Define $d: X \times X \rightarrow[0, \infty)$ in the following way:

$$
d(x, y)= \begin{cases}0, & \text { if } x=y \\ 1, & \text { if } x \neq y, \quad[\{x, y\} \subset A \text { or }\{x, y\} \subset B] \\ y, & \text { if } x \in A, y \in B .\end{cases}
$$

Notice that $d(a, b)=d(b, a)=b$ whenever $a \in A$ and $b \in B$. Furthermore, $(X, d)$ is a complete generalized metric space. Clearly, we have $(P 1)-(P 4)$. Indeed, the sequence $\{1 / n: n \in$ $\mathbb{N}\}$ converges to both 0 and 2 . There is no $r>0$ such that $B_{r}(0) \cap B_{r}(2)=\emptyset$ and hence it is not Hausdorff. It is clear that the ball $B_{2 / 3}(1 / 3)=\{0,1 / 3,2\}$ since there is no $r>0$ such that $B_{r}(0) \subset B_{2 / 3}(1 / 3)$; that is, open balls may not be an open set. The function $d$ is not continuous since $\lim _{n \rightarrow \infty} d(1 / n, 1 / 2) \neq$ $d(0,1 / 2)$ although $\lim _{n \rightarrow \infty} 1 / n=0$. For more details, see, e.g., $[6,7]$.
Regarding the weakness of the topology of generalized metric space, mentioned above, the authors add some additional conditions to get the analog of existing fixed point results in the literature; see, e.g., [8-15]. Very recently, Suzuki [16] underlined the importance of generalized metric space by emphasizing that generalized metric space and metric space have no compatible topology.

The following is the definition of the notion of generalized quasimetric space defined by Lin et al. [4]

Definition 4. Let $X$ be a nonempty set and let $d: X \times X \rightarrow$ $[0, \infty)$ be a mapping such that, for all $x, y \in X$ and for all distinct points $u, v \in X$ each of them different from $x$ and $y$, one has

(i) $d(x, y)=0$ if and only if $x=y$;

(ii) $d(x, y) \leq d(x, u)+d(u, v)+d(v, y)$.

Then $(X, d)$ is called a generalized quasimetric space (or shortly g.q.m.s).

It is evident that any generalized metric space is a generalized quasimetric space, but the converse is not true in general. We give an example to show that not every generalized quasimetric on a set $X$ is a generalized metric on $X$.

Example 5 (see [4]). Let $X=\{t, 2 t, 3 t, 4 t, 5 t\}$ with $t>0$ be a constant, and we define $d: X \times X \rightarrow[0, \infty)$ by

(1) $d(x, x)=0$, for all $x \in X$;

(2) $d(t, 2 t)=d(2 t, t)=3 s$;

(3) $d(t, 3 t)=d(2 t, 3 t)=d(3 t, t)=d(3 t, 2 t)=s$;

(4) $d(t, 4 t)=d(2 t, 4 t)=d(3 t, 4 t)=d(4 t, t)=d(4 t, 2 t)=$ $d(4 t, 3 t)=2 s$

(5) $d(t, 5 t)=d(2 t, 5 t)=d(3 t, 5 t)=d(4 t, 5 t)=(3 / 2) s$;

(6) $d(5 t, t)=d(5 t, 2 t)=d(5 t, 3 t)=d(5 t, 4 t)=(5 / 4) s$,

where $s>0$ is a constant. Then $(X, d)$ is a generalized quasimetric space, but it is not a generalized metric space, because

$$
d(t, 5 t)=\frac{3}{2} s \neq d(5 t, t)=\frac{5}{4} s .
$$

We next give the definitions of convergence and completeness on generalized quasimetric spaces.

Definition 6 (see [4]). Let $(X, d)$ be a g.q.m.s; let $\left\{x_{n}\right\}$ be a sequence in $X$ and $x \in X$. We say that $\left\{x_{n}\right\}$ is g.q.m.s convergent to $x$ if and only if

$$
\lim _{n \rightarrow \infty} d\left(x_{n}, x\right)=\lim _{n \rightarrow \infty} d\left(x, x_{n}\right)=0 .
$$

Definition 7 (see [4]). Let $(X, d)$ be a g.q.m.s and let $\left\{x_{n}\right\}$ be a sequence in $X$. We say that $\left\{x_{n}\right\}$ is left-Cauchy if and only if for every $\varepsilon>0$ there exists $k \in \mathbb{N}$ such that $d\left(x_{n}, x_{m}\right)<\varepsilon$ for all $n \geq m>k$. We say that $\left\{x_{n}\right\}$ is right-Cauchy if and only if for every $\varepsilon>0$ there exists $k \in \mathbb{N}$ such that $d\left(x_{n}, x_{m}\right)<\varepsilon$ for all $m \geq n>k$. We say that $\left\{x_{n}\right\}$ is Cauchy if and only if for every $\varepsilon>0$ there exists $k \in \mathbb{N}$ such that $d\left(x_{n}, x_{m}\right)<\varepsilon$ for all $m, n>k$. 
Remark 8. A sequence $\left\{x_{n}\right\}$ in a g.q.m.s is Cauchy if and only if it is left-Cauchy and right-Cauchy.

Definition 9 (see [4]). Let $(X, d)$ be a g.q.m.s. We say that

(1) $(X, d)$ is left-complete if and only if each left-Cauchy sequence in $X$ is convergent;

(2) $(X, d)$ is right-complete if and only if each rightCauchy sequence in $X$ is convergent;

(3) $(X, d)$ is complete if and only if each Cauchy sequence in $X$ is convergent.

Notice that, in the literature in several reports for fixed point results in generalized metric space, an additional but superfluous condition, "Hausdorffness," was assumed. Recently, Jleli and Samet [17], Kirk and Shahzad [18], Karapinar [19], Kadeburg, and Radenović [7], and Aydi et al. [20] reported new some fixed point results by removing the assumption of Hausdorffness in the context of generalized metric spaces. The following crucial lemma is inspired from $[7,17]$.

Lemma 10. Let $(X, d)$ be a generalized quasimetric space and let $\left\{x_{n}\right\}$ be a Cauchy sequence in $X$ such that $x_{m} \neq x_{n}$ whenever $m \neq n$. Then the sequence $\left\{x_{n}\right\}$ can converge to at most one point.

Proof. Given $\varepsilon>0$, since $\left\{x_{n}\right\}$ is a Cauchy sequence, there exists $k_{0} \in \mathbb{N}$ such that

$$
d\left(x_{n}, x_{m}\right)<\varepsilon, \quad \forall m, n>k_{0} .
$$

We use the method of Reductio ad absurdum. Suppose, on the contrary, that there exist two distinct points $x$ and $y$ in $X$ such that the sequence $\left\{x_{n}\right\}$ converges to $x$ and $y$; that is,

$$
\begin{aligned}
& \lim _{n \rightarrow \infty} d\left(x_{n}, x\right)=\lim _{n \rightarrow \infty} d\left(x, x_{n}\right)=0, \\
& \lim _{n \rightarrow \infty} d\left(x_{n}, y\right)=\lim _{n \rightarrow \infty} d\left(y, x_{n}\right)=0 .
\end{aligned}
$$

By assumption for any $n \in \mathbb{N}, x_{n} \neq x_{m}$, and since $x \neq y$, there exists $k_{1} \in \mathbb{N}$ such that $x_{n} \neq x$ and $x_{n} \neq y$ for any $n>k_{1} \geq k_{0}$. Due to quadrilateral inequality, we have

$$
d(x, y) \leq d\left(x, x_{n}\right)+d\left(x_{n}, x_{m}\right)+d\left(x_{m}, y\right) .
$$

Letting $n, m \rightarrow \infty$, we can obtain that $d(x, y)=0$ by regarding (5) and (6). Hence, we get $x=y$ which is a contradiction.

\section{Main Results}

In this section, we state and prove the main result of this paper. We start by introducing the following family of functions.

Let $\Psi$ be the family of functions $\psi:[0, \infty) \rightarrow[0, \infty)$ satisfying the following conditions:

$\left(\Psi_{1}\right) \psi$ is nondecreasing;
$\left(\Psi_{2}\right) \sum_{n=1}^{+\infty} \psi^{n}(t)<\infty$ for all $t>0$, where $\psi^{n}$ is the $n$th iterate of $\psi$.

These functions are known in the literature as (c)-comparison functions. It is easily proved that if $\psi$ is a (c)-comparison function, then $\psi(t)<t$ for any $t>0$. For more details about such function, we refer the reader to [21,22]. In this study, we discuss the notion of $\alpha$-admissible mappings; see, e.g., [2327]. The following definition was introduced in [23].

Definition 11. Let $f: X \rightarrow X$ be a self-mapping of a set $X$ and $\alpha: X \times X \rightarrow \mathbb{R}^{+}$. Then $f$ is called a $\alpha$-admissible if

$$
x, y \in X, \quad \alpha(x, y) \geq 1 \Longrightarrow \alpha(f x, f y) \geq 1 .
$$

In what follows we define the $(\alpha-\psi)$-contractive mapping in the setting of generalized quasimetric space.

Definition 12. Let $(X, d)$ be a g.q.m.s. and let $f: X \rightarrow X$ be a given mapping. We say that $f$ is an $(\alpha-\psi)$-contractive mapping if there exist two functions $\alpha: X \times X \rightarrow[0, \infty)$ and $\psi \in \Psi$ such that

$$
\alpha(x, y) d(f x, f y) \leq \psi(d(x, y)), \quad \forall x, y \in X .
$$

Now, we state the following fixed point theorem.

Theorem 13. Let $(X, d)$ be a complete g.q.m.s, and let $f$ : $X \rightarrow X$ be an $(\alpha-\psi)$-contractive mapping. Suppose that

(i) $f$ is $\alpha$-admissible;

(ii) there exists $x_{0} \in X$ such that $\alpha\left(x_{0}, f x_{0}\right) \geq 1$, $\alpha\left(f x_{0}, x_{0}\right) \geq 1, \alpha\left(x_{0}, f^{2} x_{0}\right) \geq 1$, and $\alpha\left(f^{2} x_{0}, x_{0}\right) \geq 1 ;$

(iii) $f$ is continuous.

Then $f$ has a periodic point.

Proof. Due to statement (ii) of theorem, there exists $x_{0} \in X$ which is an arbitrary point such that $\alpha\left(x_{0}, f x_{0}\right) \geq 1$ and $\alpha\left(x_{0}, f x_{0}\right) \geq 1$. We will construct a sequence $\left\{x_{n}\right\}$ in $X$ by $x_{n+1}=f x_{n}=f^{n+1} x_{0}$ for all $n \geq 0$. If we have $x_{n_{0}}=x_{n_{0}+1}$ for some $n_{0}$, then $u=x_{n_{0}}$ is a fixed point of $f$. Hence, for the rest of the proof, we presume that

$$
x_{n} \neq x_{n+1} \quad \forall n .
$$

Since $f$ is $\alpha$-admissible, we have

$$
\begin{aligned}
\alpha\left(x_{0}, x_{1}\right) & =\alpha\left(x_{0}, f x_{0}\right) \geq 1 \\
& \Longrightarrow \alpha\left(f x_{0}, f x_{1}\right)=\alpha\left(x_{1}, x_{2}\right) \geq 1 .
\end{aligned}
$$

Utilizing the expression above, we obtain that

$$
\alpha\left(x_{n}, x_{n+1}\right) \geq 1, \quad \forall n=0,1, \ldots
$$

By repeating the same steps with starting with the assumption $\alpha\left(x_{1}, x_{0}\right)=\alpha\left(f x_{0}, x_{0}\right) \geq 1$, we conclude that

$$
\alpha\left(x_{n+1}, x_{n}\right) \geq 1, \quad \forall n=0,1, \ldots
$$


In a similar way, we derive that

$$
\begin{aligned}
\alpha\left(x_{0}, x_{2}\right) & =\alpha\left(x_{0}, f^{2} x_{0}\right) \geq 1 \\
& \Longrightarrow \alpha\left(f x_{0}, f x_{2}\right)=\alpha\left(x_{1}, x_{3}\right) \geq 1 .
\end{aligned}
$$

Recursively, we get that

$$
\alpha\left(x_{n}, x_{n+2}\right) \geq 1, \quad \forall n=0,1, \ldots
$$

Analogously, we can easily derive that

$$
\alpha\left(x_{n+2}, x_{n}\right) \geq 1, \quad \forall n=0,1, \ldots
$$

Step 1. We will show that $\lim _{n \rightarrow \infty} d\left(x_{n}, x_{n+1}\right)=0$ and $\lim _{n \rightarrow \infty} d\left(x_{n}, x_{n+2}\right)=0$. Regarding (8) and (12), we deduce that

$$
\begin{aligned}
d\left(x_{n}, x_{n+1}\right) & =d\left(f x_{n-1}, f x_{n}\right) \\
& \leq \alpha\left(x_{n-1}, x_{n}\right) d\left(f x_{n-1}, f x_{n}\right) \\
& \leq \psi\left(d\left(x_{n-1}, x_{n}\right)\right)
\end{aligned}
$$

for all $n \geq 1$.

Iteratively, we find that

$$
d\left(x_{n}, x_{n+1}\right) \leq \psi^{n}\left(d\left(x_{0}, x_{1}\right)\right) \quad \forall n \geq 1 .
$$

Similarly,

$$
d\left(x_{n}, x_{n+2}\right) \leq \psi^{n}\left(d\left(x_{0}, x_{2}\right)\right) \quad \forall n \geq 1 .
$$

By the properties of $\psi$ we can conclude that $\lim _{n \rightarrow \infty} \psi^{n}\left(d\left(x_{0}, x_{1}\right)\right)=0$; that is,

$$
\lim _{n \rightarrow \infty} d\left(x_{n}, x_{n+1}\right)=0 .
$$

Similarly, $\lim _{n \rightarrow \infty} \psi^{n}\left(d\left(x_{0}, x_{2}\right)\right)=0$, that is;

$$
\lim _{n \rightarrow \infty} d\left(x_{n}, x_{n+2}\right)=0 \text {. }
$$

Step 2. We will prove that $\left\{x_{n}\right\}$ is a right-Cauchy sequence; that is,

$$
\lim _{n \rightarrow \infty} d\left(x_{n}, x_{n+k}\right)=0 \quad \forall k \in \mathbb{N} \text {. }
$$

The cases $k=1$ and $k=2$ are proved, respectively, by (20) and (21). Now, take $k \geq 3$ arbitrary. It is sufficient to examine two cases.

Case (I). Suppose that $k=2 m+1$, where $m \geq 1$. Then, by using Step 1 and the quadrilateral inequality together with (18), we find

$$
\begin{aligned}
d\left(x_{n}, x_{n+k}\right)= & d\left(x_{n}, x_{n+2 m+1}\right) \\
\leq & d\left(x_{n}, x_{n+1}\right)+d\left(x_{n+1}, x_{n+2}\right) \\
& +\cdots+d\left(x_{n+2 m}, x_{n+2 m+1}\right) \\
\leq & \sum_{p=n}^{n+2 m} \psi^{p}\left(d\left(x_{0}, x_{1}\right)\right) \\
\leq & \sum_{p=n}^{+\infty} \psi^{p}\left(d\left(x_{0}, x_{1}\right)\right) \longrightarrow 0 \quad \text { as } n \longrightarrow \infty .
\end{aligned}
$$

Case (II). Suppose that $k=2 m$, where $m \geq 2$. Again, by applying the quadrilateral inequality and Step 1 together with (18) and (19), we find

$$
\begin{aligned}
d\left(x_{n}, x_{n+k}\right)= & d\left(x_{n}, x_{n+2 m}\right) \\
\leq & d\left(x_{n}, x_{n+2}\right)+d\left(x_{n+2}, x_{n+3}\right) \\
& +\cdots+d\left(x_{n+2 m-1}, x_{n+2 m}\right) \\
\leq & d\left(x_{n}, x_{n+2}\right)+\sum_{p=n+2}^{n+2 m-1} \psi^{p}\left(d\left(x_{0}, x_{1}\right)\right) \\
\leq & d\left(x_{n}, x_{n+2}\right) \\
& +\sum_{p=n}^{+\infty} \psi^{p}\left(d\left(x_{0}, x_{1}\right)\right) \longrightarrow 0 \text { as } n \longrightarrow \infty .
\end{aligned}
$$

By combining the expressions (23) and (24), we have

$$
\lim _{n \rightarrow \infty} d\left(x_{n}, x_{n+k}\right)=0 \quad \forall k \geq 3 .
$$

We conclude that $\left\{x_{n}\right\}$ is a right-Cauchy sequence in $(X, d)$.

In the same way $\left\{x_{n}\right\}$ is a left-Cauchy sequence in $(X, d)$. So it is a Cauchy sequence. Since $X$ is a complete g.q.m.s, there exists $u \in X$ such that

$$
\lim _{n \rightarrow \infty} d\left(x_{n}, u\right)=\lim _{n \rightarrow \infty} d\left(u, x_{n}\right)=0 .
$$

Also, we can easily see that $x_{n} \neq x_{m}$ for whenever $m \neq n$. Indeed, if $x_{n}=x_{m}$, for some $m, n \in \mathbb{N}$ with $n<m$, then

$$
\begin{aligned}
d\left(x_{n}, x_{n+1}\right) & =d\left(x_{m}, x_{m+1}\right) \\
& \leq \psi^{m-n} d\left(x_{n}, x_{n+1}\right)<d\left(x_{n}, x_{n+1}\right),
\end{aligned}
$$

which is a contradiction. Analogously, we derive the same conclusion for the case $n>m$. Therefore, we conclude that the sequence $\left\{x_{n}\right\}$ cannot have two limits due to Lemma 10.

Step 3. We claim that $f$ has a periodic point in $X$. Suppose, on the contrary, that $f$ has no periodic point. Since $f$ is continuous, from Step 2, we have $u=f u,(p=1)$ which contradicts the assumption that $f$ has no periodic point. Therefore, there exists $u \in X$ such that $u=f^{p}(u)$ for some $p \in \mathbb{N}$. So $f$ has a periodic point in $X$.

Now, we state the following fixed point theorem.

Theorem 14. Let $(X, d)$ be a complete g.q.m.s, and let $f$ : $X \rightarrow X$ be an $(\alpha-\psi)$-contractive mapping. Suppose that

(i) $f$ is $\alpha$-admissible;

(ii) there exists $x_{0} \in X$ such that $\alpha\left(x_{0}, f x_{0}\right) \geq 1$, $\alpha\left(f x_{0}, x_{0}\right) \geq 1, \alpha\left(x_{0}, f^{2} x_{0}\right) \geq 1$, and $\alpha\left(f^{2} x_{0}, x_{0}\right) \geq 1 ;$

(iii) if $\left\{x_{n}\right\}$ is a sequence in $X$ such that $\alpha\left(x_{n}, x_{n+1}\right) \geq 1$ for all $n$ and $x_{n} \rightarrow x \in X$ as $n \rightarrow \infty$, then $\alpha\left(x_{n}, x\right) \geq 1$ for all $n$.

Then $f$ has a periodic point. 
Proof. Following the proof of Theorem 13, we know that the sequence $\left\{x_{n}\right\}$ defined by $x_{n+1}=f x_{n}$ for all $n \geq 0$ converges for some $u \in X$. It is sufficient to show that $f$ admits a periodic point. Suppose, on the contrary, that $f$ has no periodic point. Notice that $x_{n} \neq u$ and $x_{n} \neq f u$ for sufficiently large $n$. By the quadrilateral inequality, for this $n$, we have

$$
d(u, f u) \leq d\left(u, x_{n}\right)+d\left(x_{n}, x_{n+1}\right)+d\left(x_{n+1}, f u\right) .
$$

On account of the fact that $\psi(t)<t$, for all $t>0$, and regarding the assumption (iii), we get that

$$
\begin{aligned}
d(u, f u) & \leq d\left(u, x_{n}\right)+d\left(x_{n}, x_{n+1}\right)+d\left(x_{n+1}, f u\right) \\
& \leq d\left(u, x_{n}\right)+d\left(x_{n}, x_{n+1}\right)+d\left(f x_{n}, f u\right) \\
& \leq d\left(u, x_{n}\right)+d\left(x_{n}, x_{n+1}\right)+\alpha\left(x_{n}, u\right) d\left(f x_{n}, f u\right) \\
& \leq d\left(u, x_{n}\right)+d\left(x_{n}, x_{n+1}\right)+\psi\left(d\left(x_{n}, u\right)\right) \\
& <d\left(u, x_{n}\right)+d\left(x_{n}, x_{n+1}\right)+d\left(x_{n}, u\right) .
\end{aligned}
$$

Letting $n \rightarrow \infty$ in the above equality, from (20) we find that

$$
\lim _{n \rightarrow \infty} d\left(x_{n}, u\right)=0 \text { and so } \lim _{n \rightarrow \infty} d\left(x_{n+1}, f u\right)=0 \text {. }
$$

Again from (20), (26), and (30), we can obtain $d(u, f u)=0$ and hence $u$ is a periodic point of $f$.

In what follows we give an example to illustrate Theorem 13.

Example 15. In Example 5 define the mapping $f: X \rightarrow X$ as

$$
f x \stackrel{\text { def }}{=} \begin{cases}5 t & \text { if } x \neq 4 t \text { or } t \\ t & \text { if } x=4 t \text { or } t\end{cases}
$$

First, we can see easily that the classic Branciari contraction [5] cannot be applied in this case since

$$
d(f 3 t, f t)=\frac{5}{4} s>s=d(3 t, t) .
$$

Now we define the mapping $\alpha$ from $X \times X \rightarrow[0, \infty)$ by

$$
\begin{aligned}
\alpha(x, x) & =\alpha(t, 4 t)=\alpha(2 t, 3 t)=\alpha(2 t, 5 t) \\
& =\alpha(3 t, 5 t)=1 ; \quad \text { otherwise } \alpha(x, y)=0,
\end{aligned}
$$

for all $x, y \in X$. For $\psi(r)=r / 2$, where $r \geq 0$, we have

$$
\alpha(x, y) d(f x, f y) \leq \frac{1}{2} d(x, y)
$$

Obviously $f$ is $\alpha$-admissible and also for $x_{0}=t$ we have

$$
\alpha(t, f t)=\alpha(f t, t)=\alpha\left(t, f^{2} t\right)=\alpha\left(f^{2} t, t\right)=\alpha(t, t)=1 .
$$

Finally $f$ is continuous. Therefore $f$ satisfies in Theorem 13 and we can see that $f$ has two fixed points $t$ and $3 t$.
2.1. Existence Theorem. Let $(X, d)$ be a g.q.m.s and $\operatorname{Per}\left(f_{X}\right)$ denote the set of periodic points of $f: X \rightarrow X$.

Property (E). For all $a \in \operatorname{Per}\left(f_{X}\right)$, we have $\alpha\left(f^{p} a, f^{p+1} a\right) \geq 1$ and $\alpha\left(f^{p+1} a, f^{p} a\right) \geq 1$, for any $p \geq 1$.

Theorem 16. Adding Property (E) to the hypotheses of Theorem 13 (res. Theorem 14), one obtains existence of a fixed point of $f$.

Proof. Suppose that $a$ is a periodic point of $f$; that is, $f^{p} a=a$. If $p=1$, then $a$ is a fixed point of $f$; that is, $f^{p} a=f a=a$. Assume that $p>1$. We will show that $z=f^{p-1} a$ is a fixed point of $f$.

Suppose, on the contrary, that $f^{p-1} a \neq f^{p} a$. Then $d\left(f^{p-1} a, f^{p} a\right)>0, d\left(f^{p} a, f^{p-1} a\right)>0, \psi\left(d\left(f^{p-1} a, f^{p} a\right)\right)>0$, and $\psi\left(d\left(f^{p} a, f^{p-1} a\right)\right)>0$.

By Property $(E)$, we have $\alpha\left(a, f^{p} a\right) \geq 1$ and $\alpha\left(f^{p} a, a\right) \geq$ 1. Due to (9), we can obtain

$$
\begin{aligned}
d(a, f a) & =d\left(f^{p} a, f^{p+1} a\right) \\
& \leq \alpha\left(f^{p} a, f^{p+1} a\right) d\left(f^{p} a, f^{p+1} a\right) \\
& \leq \psi\left(d\left(f^{p-1} a, f^{p} a\right)\right) .
\end{aligned}
$$

Due to property $\psi(t)<t$, we get that

$$
d(a, f a)<d\left(f^{p-1} a, f^{p} a\right)
$$

Again by (9), we have

$$
\begin{aligned}
d\left(f^{p-1} a, f^{p} a\right) & \leq \alpha\left(f^{p-1} a, f^{p} a\right) d\left(f^{p-1} a, f^{p} a\right) \\
& \leq \psi\left(d\left(f^{p-2} a, f^{p-1} a\right)\right) \\
& \vdots \\
& \leq \psi^{p}(d(a, f a)) \\
& <d(a, f a) .
\end{aligned}
$$

Consequently, we get the following contradiction: $d(a, f a)<d(a, f a)$. Hence, the assumption that $z$ is not a fixed point of $f$ is not true and thus $z=f^{p-1} a$ is a fixed point of $f$.

To assure the uniqueness of the fixed point, we will consider the following properties.

$\operatorname{Property}(U)$. For all $x, y \in \operatorname{Fix}(f)$, we have $\alpha(x, y) \geq 1$.

Theorem 17. Adding property $(U)$ to the hypotheses of Theorem 16, one obtains uniqueness of the fixed point of $f$.

Proof. Suppose that $u$ and $v$ are two distinct fixed points of $f$. By property $(U), \alpha(T u, T v)=\alpha(u, v) \geq 1$. 
Thus by $\alpha$-admissibility of $f$ and the above relation, we can obtain

$$
\begin{aligned}
d(u, v) & \leq \alpha(u, v) d(u, v) \\
& =\alpha(f u, f v) d(f u, f v) \\
& \leq \psi d(u, v)<d(u, v),
\end{aligned}
$$

which is a contradiction. Therefore $u=v$.

\section{Consequences}

Definition 18. Let $(X, d)$ be a g.q.m.s, and let $f: X \rightarrow X$ be a function satisfying

$$
d(f x, f y) \leq \psi(d(x, y))
$$

for all $x, y \in X$. Then $f$ is said to be a $\psi$-contractive mapping.

Theorem 19. Let $(X, d)$ be a complete g.q.m.s, and let $f$ be a continuous $\psi$-contractive mapping. Then $f$ is a unique point $u$ in $X$.

Proof. It is sufficient to take $\alpha(x, y)=1$ for all $x, y \in X$.

Theorem 20. Let $(X, d)$ be a complete g.q.m.s, and let $f$ be a continuous mapping. Suppose that there exists $k \in[0,1)$ such that

$$
d(f x, f y) \leq k d(x, y), \quad \forall x, y \in X
$$

Then $f$ is a unique point $u$ in $X$.

Proof. Take $\psi(t)=k t$, where $k \in[0,1)$. It is clear that all conditions of Theorem 19 are satisfied.

\section{Conclusion}

It is evident that almost all fixed point theorems, in the context of generalized metric spaces, can be represented in the setting of generalized quasimetric spaces. Thus, all fixed point results obtained in Section 2 infer the analog of the fixed point theorems in the context of generalized metric spaces. Consequently, several results in the literature (see, e.g., $[5,8,9,19,28])$ can be derived from our main results.

\section{Conflict of Interests}

The authors declare that they have no conflict of interests.

\section{Authors' Contribution}

All authors contributed equally and significantly in writing this paper. All authors read and approved the final paper.

\section{Acknowledgment}

The authors thank the anonymous referees for their remarkable comments, suggestion, and ideas that helped to improve this paper.

\section{References}

[1] Z. Mustafa and B. Sims, "A new approach to generalized metric spaces," Journal of Nonlinear and Convex Analysis, vol. 7, no. 2, pp. 289-297, 2006.

[2] M. Jleli and B. Samet, "Remarks on G-metric spaces and fixed point theorems," Fixed Point Theory and Applications, vol. 2012, article 210, 2012.

[3] N. Bilgili, E. Karapınar, and B. Samet, "Generalized $\alpha-\psi$ contractive mappings in quasi-metric spaces and related fixed-point theorems," Journal of Inequalities and Applications, vol. 2014, article 36, 2014.

[4] I. Lin, C. Chen, and E. Karapınar, "Periodic points of weaker meir-keeler contractive mappings on generalized quasimetric spaces," Abstract and Applied Analysis, vol. 2014, Article ID 490450, 6 pages, 2014.

[5] A. Branciari, "A fixed point theorem of Banach-Caccioppoli type on a class of generalized metric spaces," Publicationes Mathematicae Debrecen, vol. 57, no. 1-2, pp. 31-37, 2000.

[6] I. R. Sarma, J. M. Rao, and S. S. Rao, "Contractions over generalized metric spaces," Journal of Nonlinear Science and Its Applications, vol. 2, no. 3, pp. 180-182, 2009.

[7] Z. Kadeburg and S. Radenović, "On generalized metric spaces: a survey," TWMS Journal of Pure and Applied Math, vol. 5, no. 1, pp. 3-13, 2014.

[8] A. Azam and M. Arshad, "Kannan fixed point theorem on generalized metric spaces," Journal of Nonlinear Sciences and Its Applications, vol. 1, no. 1, pp. 45-48, 2008.

[9] P. Das, "A fixed point theorem on a class of generalized metric spaces," Korean Journal of Mathematical Sciences, vol. 9, pp. 2933, 2002.

[10] M. Erhan, E. Karapınar, and T. Sekulic, "Fixed points of $(\psi, \phi)$ contractions on rectangular metric spaces," Fixed Point Theory and Applications, vol. 2012, article 138, 2012.

[11] D. Mihet, "On Kannan fixed point principle in generalized metric spaces," Journal of Nonlinear Science and its Applications: TJNSA, vol. 2, no. 2, pp. 92-96, 2009.

[12] B. Samet, "A fixed point theorem in a generalized metric space for mappings satisfying a contractive condition of integral type," International Journal of Mathematical Analysis, vol. 3, no. 25-28, pp. 1265-1271, 2009.

[13] B. Samet, "Disscussion on: a fixed point theorem of BanachCaccioppli type on a class of generalized metric spaces," Publicationes Mathematicae, vol. 76, no. 4, pp. 493-494, 2010.

[14] H. Lakzian and B. Samet, "Fixed points for $(\psi, \varphi)$-weakly contractive mappings in generalized metric spaces," Applied Mathematics Letters, vol. 25, no. 5, pp. 902-906, 2012.

[15] H. Aydi, E. Karapınar, and H. Lakzian, "Fixed point results on a class of generalized metric spaces," Mathematical Sciences, vol. 6, article 46, 2012.

[16] T. Suzuki, "Generalized metric spaces do not have the compatible topology," Abstract and Applied Analysis, vol. 2014, Article ID 458098, 2014.

[17] M. Jleli and B. Samet, "The Kannan's fixed point theorem in a cone rectangular metric space," Journal of Nonlinear Science and Its Applications, vol. 2, no. 3, pp. 161-167, 2009.

[18] W. A. Kirk and N. Shahzad, "Generalized metrics and Caristi's theorem," Fixed Point Theory and Applications, vol. 2013, article 129, 2013.

[19] E. Karapınar, "Discussion on $\alpha-\psi$ contractions on generalized metric spaces," Abstract and Applied Analysis, vol. 2014, Article ID 962784, 7 pages, 2014. 
[20] H. Aydi, E. Karapınar, and B. Samet, "Fixed points for generalized (alpha,psi)-contractions on generalized metric spaces," Journal of Inequalities and Applications, vol. 2014, article 229, 2014.

[21] I. A. Rus, Generalized Contractions and Applications, Cluj University Press, Cluj-Napoca, Romania, 2001.

[22] R. M. Bianchini and M. Grandolfi, "Trasformazioni di tipo contrattivo generalizzato in uno spazio metrico," Atti della Accademia Nazionale dei Lincei: Rendiconti: Classe di Scienze Fisiche, Matematiche e Naturali, vol. 45, pp. 212-216, 1968.

[23] B. Samet, C. Vetro, and P. Vetro, "Fixed point theorems for $\alpha--\psi$-contractive type mappings," Nonlinear Analysis: Theory, Methods \& Applications, vol. 75, no. 4, pp. 2154-2165, 2012.

[24] N. Hussain, E. Karapınar, P. Salimi, and P. Vetro, "Fixed point results for $G^{m}$-Meir-Keeler contractive and $G$ - $(\alpha, \psi)$-MeirKeeler contractive mappings," Fixed Point Theory and Applications, vol. 2013, article 34, 2013.

[25] N. Hussain, E. Karapınar, P. Salimi, and F. Akbar, “ $\alpha$-admissible mappings and related fixed point theorems," Journal of Inequalities and Applications, vol. 2013, article 114, 11 pages, 2013.

[26] P. Salimi and E. Karapınar, "Suzuki-Edelstein type contractions via auxiliary functions," Mathematical Problems in Engineering, vol. 2013, Article ID 648528, 8 pages, 2013.

[27] L. B. Ćirić, S. M. Alsulami, P. Salimi, and P. Vetro, "PPF dependent fixed point results for triangular $\alpha_{c}$-admissible mappings," The Scientific World Journal, vol. 2014, Article ID 673647, 10 pages, 2014.

[28] M. A. Alghamdi, C.-M. Chen, and E. Karapınar, "A generalized weaker (alpha-phi-varphi)-contractive mappings and related fixed point results in complete generalized metric spaces," Abstract and Applied Analysis, vol. 2014, Article ID 985080, 10 pages, 2014. 


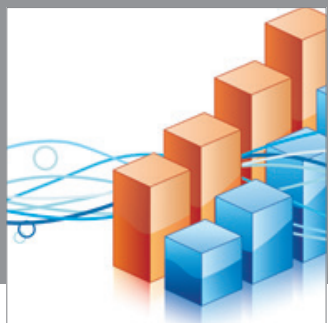

Advances in

Operations Research

mansans

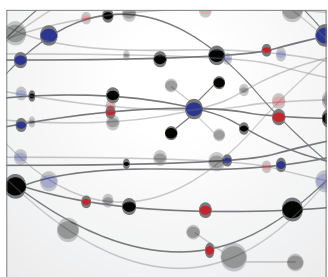

The Scientific World Journal
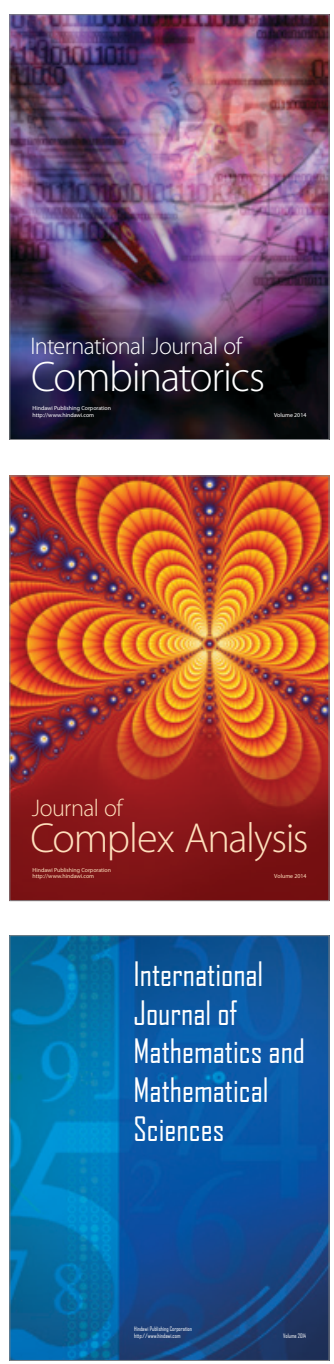
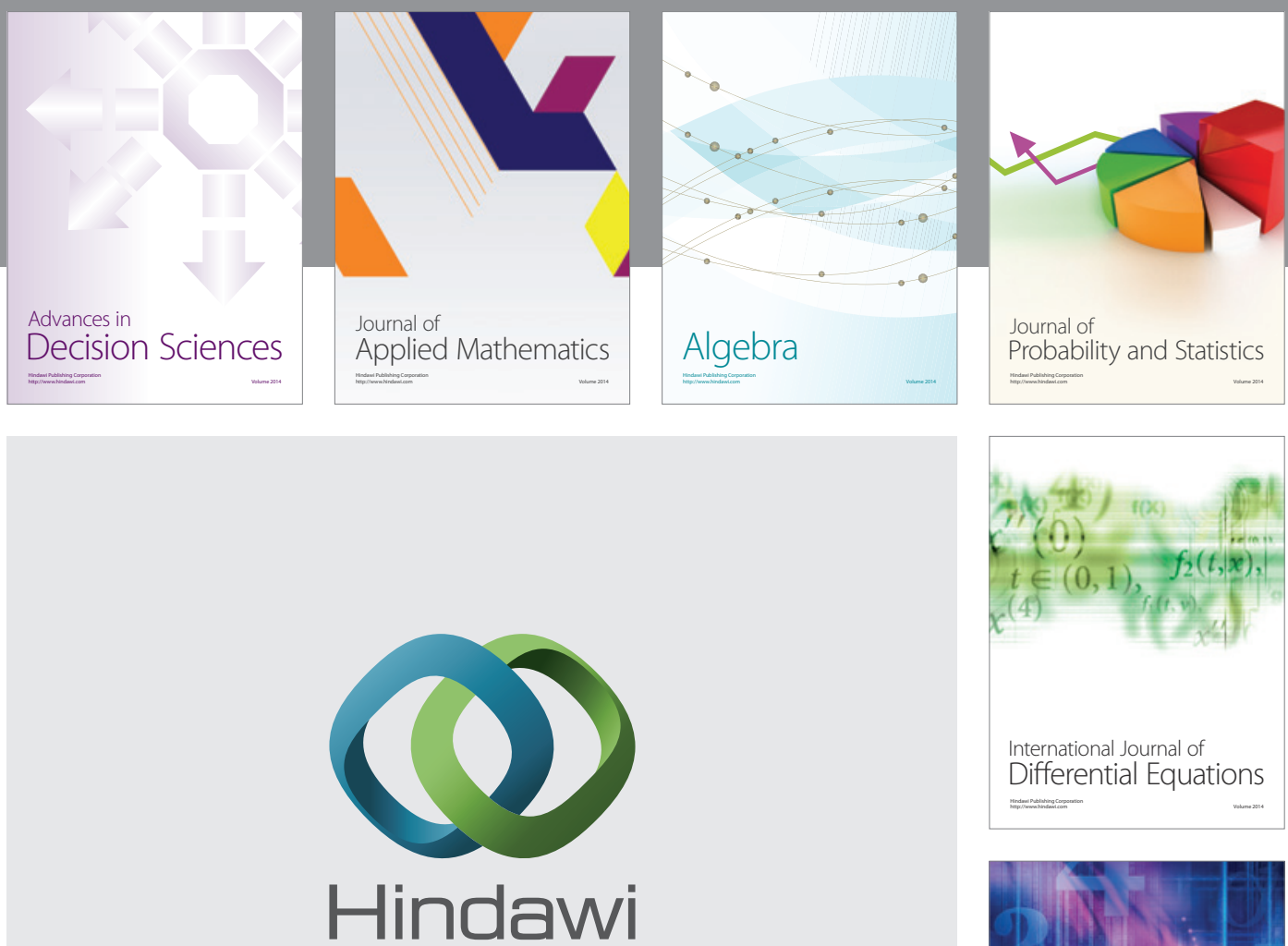

Submit your manuscripts at http://www.hindawi.com
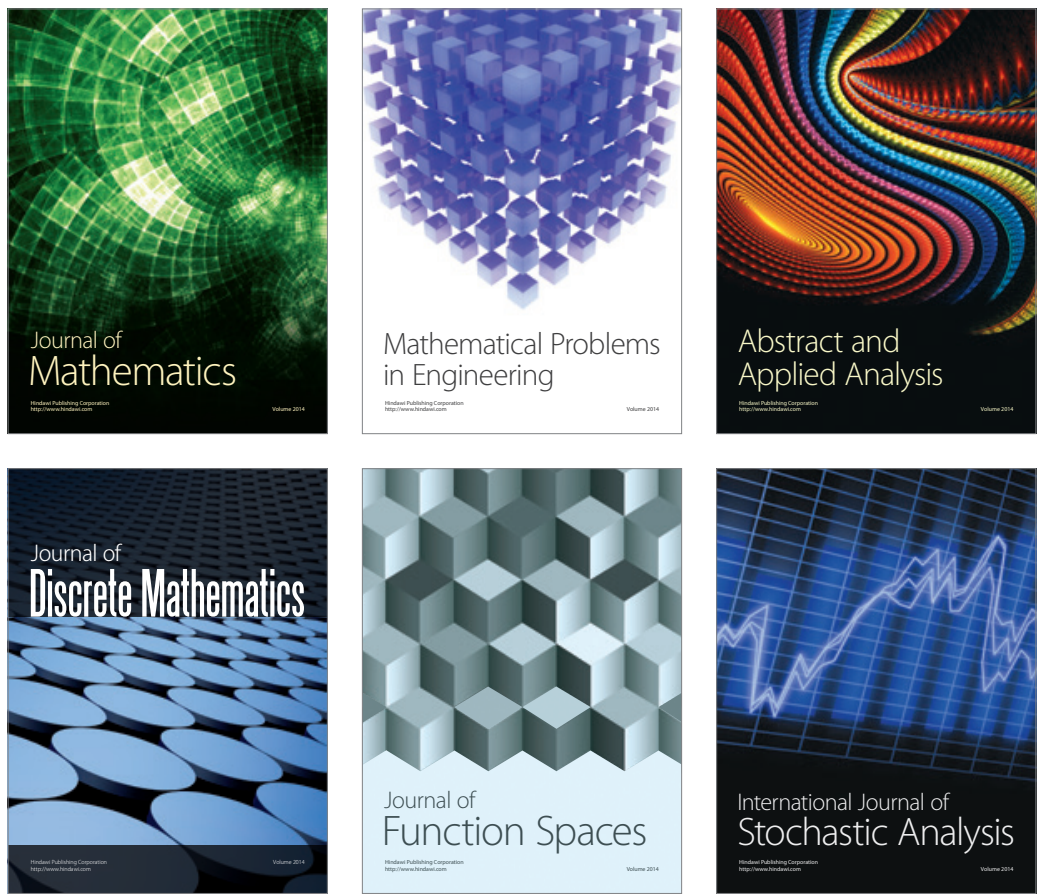

Journal of

Function Spaces

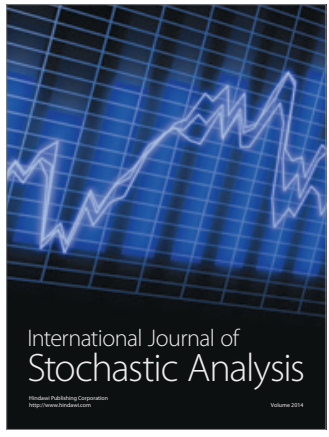

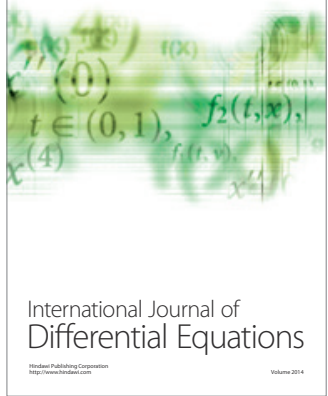
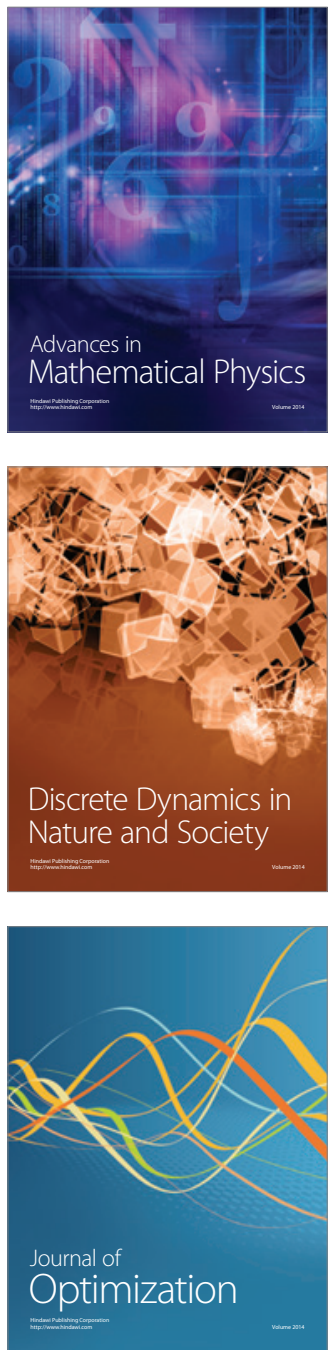